\title{
Alat Pendeteksi Kebocoran Gas Beracun Co Pada Mobil Dengan Array SENSOR MENGgUNAKAN FuZzY CONTROLler
}

\author{
${ }^{1}$ Slamet Widodo dan ${ }^{2}$ Eka Rahma Sari \\ ${ }^{1,2}$ Jurusan Teknik Komputer Politeknik Negeri Sriwijaya, Jl. Srijaya Negara Bukit Besar-Palembang \\ 30139 \\ e-mail: ${ }^{1}$ slamet_widodo2003@yahoo.com
}

\begin{abstract}
Abstrak. Perkembangan teknologi otomotif sekarang ini semakin pesat yaitu dengan fasilitas accessories mobil yang semakin lengkap. Namun berbagai fasilitas yang terdapat dalam mobil tanpa disadari menyimpan ancaman bahaya bagi pengguna mobil salah satunya ketika system pada AC (Air Conditioner) terjadi kebocoran maka gas CO (karbon monoksida) akan memenuhi ruang mobil yang tertutup. Gas CO ini sangat berbahaya karena gas ini tidak berwarna, tidak berbau, dan tidak berasa sehingga sulit untuk dideteksi yang dapat menyebabkan orang yang ada didalam mobil menjadi mati lemas tanpa disadari karena menghirup gas CO yang bocor. Dengan fenomena tersebut dibutuhkan sebuah alat yang dapat mendeteksi dan mengontrol kebocoran gas $\mathrm{CO}$ untuk memberikan rasa aman kepada pengguna mobil. Alat ini menggunakan kendali logika fuzzy sebagai proses pengambilan keputusan sebagai hasil nilai dari inferensi kerja array sensor. Pengendali utama pada sistem menggunakan mikrokontroller ATmega32. Ketika array sensor yaitu TGS2442 dan TGS2600 mendeteksi kadar gas CO >29,0 ppm berarti dalam status bahaya sehingga buzzer akan aktif diikuti motor DC yang menggerakkan kaca mobil agar terbuka. Berdasarkan lima kali pengujian yang dilakukan didapatkanlah ratarata selisih error output gas sebesar 0.29 ppm disaat kondisi aman dan 3.87 ppm disaat kondisi bahaya.
\end{abstract}

Kata Kunci: Gas beracun CO, logika fuzzy, Array sensor

\section{Pendahuluan}

Semakin berkembangnya kendaraan bermotor dengan sangat pesat, maka banyak juga gas buang yang akan keluar dari sisa pembakaran kendaraan tersebut. Gas buang pada kendaraan adalah sisa dari hasil pembakaran berupa air $\left(\mathrm{H}_{2} \mathrm{O}\right)$, Karbon Monoksida (CO), Karbon Dioksida $\left(\mathrm{CO}_{2}\right)$, Nitrogen Oksida $\left(\mathrm{NO}_{\mathrm{x}}\right)$, Sulfur Dioxide $\left(\mathrm{SO}_{2}\right)$ dan senyawa Hidrat Carbon (HC) sebagai ketidak sempurnaan proses pembakaran serta partikel lepas. Apabila terhirup, gas $\mathrm{CO}$ akan ikut peredaran darah dan akan menghalangi masuknya oksigen yang akan dibutuhkan oleh tubuh. Semua itu adalah resiko dengan berkembangnya pola pikir manusia untuk meningkatkan fasilitas pada kendaraan. Kendaraan merupakan suatu sarana transportasi yang sangat penting yang banyak digunakan oleh manusia dalam menjalankan kegiatan. Termasuk salah satu yang populer adalah mobil. Maka dibuatlah beberapa fasilitas seperti halnya AC (Air Conditioner), Power Window, yang dapat memberikan kenyamanan pada pengguna mobil.

Namun dari berbagai keuntungan yang di dapat dari beberapa tekonologi tersebut, bukan berarti teknologi tersebut tanpa error. Khusunya adalah AC (Air Conditioner). Jika pada mesin terjadi pembakaran yang tidak sempurna dan akan menghasilkan gas CO, Gas akan masuk melalui lubang AC (Air Conditioner) apabila terjadi kebocoran pada lubang AC (Air Conditioner). Gas ini sangat berbahaya karena 


\section{Slamet Widodo, et al.}

tidak berwarna, tidak berbau, dan tidak berasa. Kondisi ini sangat berbahaya bagi manusia karena dapat menyebabkan kematian.

Karbon monoksida, rumus kimia $C O$, adalah gas yang tak berwarna, tak berbau, dan tak berasa. Ia terdiri dari satu atom karbon yang secara kovalen berikatan dengan satu atom oksigen. Dalam ikatan ini, terdapat dua ikatan kovalen dan satu ikatan kovalen koordinasi antara atom karbon dan oksigen. Karbon monoksida dihasilkan dari pembakaran tak sempurna dari senyawa karbon, sering terjadi pada mesin pembakaran dalam. Karbon monoksida terbentuk apabila terdapat kekurangan oksigen dalam proses pembakaran. Karbon monoksida mudah terbakar dan menghasilkan lidah api berwarna biru, menghasilkan karbon dioksida. (www.pom.go.id).

Mikrokontroler ATmega32 adalah mikrokontroler 8-bit keluaran Atmel dari keluarga AVR. Mikrokontroler ini dirancang berdasarkan arsitektur AVR RISC (Reduced Instruction Set Computer) yang mengeksekusi satu instruksi dalam satu siklus clock sehingga dapat mencapai eksekusi instruksi sebesar 1 MIPS (Million Instruction Per Second) setiap $1 \mathrm{MHZ}$ frekuensi clock yang digunakan mikrokontroler tersebut. Frekuensi clock yang digunakan dapat diatur melalui fuse bits dan kristal yang digunakan. Jika kristal yang digunakan sebesar $16 \mathrm{MHZ}$ sehingga frekuensi clock-nya sebesar 16 MHZ maka eksekusi instruksinya mencapai 16 MIPS. (Winoto, Ardi. 2010)

Sensor gas TGS 2600 digunakan untuk mendeteksi udara yang terkontaminasi, fitur sensor gas ini menggunakan tegangan yang rendah (low power consumption), memiliki sensitivitas yang tinggi terhadap udara yang terkontaminasi, serta ukurannya yang kecil. Sensor ini termasuk dalam golongan sensor analog, hal ini berarti bahwa sensor gas figaro mempunyai nilai yang variatif. Sensor ini mempunyai nilai Rs yang akan berubah bila terkena gas dan juga mempunyai sebuah pemanas (heater) yang digunakan untuk membersihkan ruangan sensor dari kontaminasi udara luar, (www.deltaelectronik.com)

Logika Fuzzy merupakan sesuatu logika yang memiliki nilai kekaburan atau kesamaran (fuzzyness) antara benar atau salah. Dalam teori logika fuzzy suatu nilai bias bernilai benar atau salah secara bersama. Namun berapa besar keberadaan dan kesalahan suatu tergantung pada bobot keanggotaan yang dimilikinya. Logika fuzzy memiliki derajat keanggotaan dalam rentang 0 hingga 1. Secara umum, logika fuzzy adalah sebuah metodologi "berhitung" dengan variabel kata-kata (linguistic), sebagai pengganti berhitung dengan bilangan. Kata-kata yang di gunakan dalam logika fuzzy memang tidak sepresisi bilangan, namun kata-kata jauh lebih dekat dengan bahasa manusia sehari-hari (Agus Naba.2009)

Proses fuzzyfikasi merupakan proses untuk mengubah variabel non-fuzzy (variabel-numerik) menjadi variabel fuzzy (variabel linguistik). Nilai masukan yang masih dalam bentuk variabel numerik yang telah dikuantisasi sebelum diolah oleh pengendali fuzzy harus diubah terlebih dahulu kedalam variabel fuzzy. Melalui fungsi keanggotaan yang telah disusun maka dari nilai-nilai masukan tersebut menjadi informasi fuzzy yang berguna nantinya untuk proses pengolahan secara fuzzy pula. Proses ini disebut fuzzyfikasi. Suatu himpunan fuzzy (fuzzy set) A dalam semesta pembicaraan (universe of discourse) $U$ dinyatakan dengan fungsi keanggitaan (membership function) $\mu_{\mathrm{A}}$, yang harganya berada dalam interval [0,1]. Secara matematika hal ini dinyatakan dengan : 
Himpunan fuzzy A dalam semesta pembicaraan U biasa dinyatakan sebagai sekumpulan pasangan elemen $\mathrm{u}(\mathrm{u}$ anggota $\mathrm{U}$ ) dan besarnya derajat keanggotaan (grade of membership) elemen tersebut, $\mu_{\mathrm{A}}$, adalah sebagai berikut :

$$
\mathrm{A}=\{(\mathrm{u}, \mu \mathrm{A}(\mathrm{u}) / \mathrm{u} \varepsilon \mathrm{U})\}
$$

Tanda '/' digunakan untuk menghubungkan sebuah elemen dengan derajat keanggotaannya. Jika U adalah diskrit maka A dapat dinyatakan dengan :

$$
\begin{aligned}
& \mathrm{A}=\mu_{\mathrm{A}}\left(\mathrm{u}_{1}\right)+\ldots+\mu_{\mathrm{A}}\left(\mathrm{u}_{\mathrm{n}}\right) / \mathrm{u}_{\mathrm{n}} \\
& \mathrm{A}=\sum_{i=1}^{n} \quad \mu_{\mathrm{A}}\left(\mathrm{u}_{\mathrm{i}}\right) / \mathrm{u}_{\mathrm{i}} \ldots \ldots \ldots
\end{aligned}
$$

Dan jika U adalah kontnu, maka himpunan fuzzy bias dinyatakan dengan :

$$
\mathrm{A}=\int_{U} \quad \mu_{\mathrm{A}}(\mathrm{u}) / \mathrm{u}
$$

Tanda '+',' $\sum$ ', dan'`' menyatakan operator union (gabungan)

Proses untuk mendapatkan besarnya derajat keanggotaan masukan yang berupa suatu variabel numerik non-fuzzy (elemen himpunan dalam suatu himpunan fuzzy di sebut fuzzyfikasi (fuzzification),(Son Kuswadi,2007).

Untuk mendeteksi gas $\mathrm{CO}$ sensor terhubung ke ADC mikrokontroler di port A dengan tegangan 5 volt DC dengan range ADC 0-1023. Untuk pendeteksian gas CO ditetapkan bahwa nilai maksimal sensor untuk mendeteksi gas $\mathrm{CO}$ adalah sebesar 30 ppm. Dari ketetapan tersebut didapatkan fungsi keanggotaan gas $\mathrm{CO}$ untuk nilai fungsi keanggotaannya dengan range 0-30 ppm. Maka agar skala fungsi keanggotaannya sesuai yaitu 30 ppm maka nilai ADC harus dibagi dengan 34 yang dapat dicari dengan persamaan berikut :

$$
\text { Nilai Pembagi ADC }=\frac{1023}{30 \mathrm{ppm}}
$$

Keterangan : Nilai pembagi $\mathrm{ADC}=34$

Nilai ADC : 1024

Gas CO (ppm) : Nilai Maksimum Gas CO (ppm)

Tahapan yang dilakukan dalam penelitian ini yaitu dengan metode perencanaan dan perancangan. Tahap perencanaan adalah menentukan suatu sistem yang akan dibuat dan mengetahui prinsip kerjanya untuk memudahkan dalam proses pembuatan alat. Langkah selanjutnya adalah membuat suatu diagram blok dari sistem ini sendiri sehingga dapat menggambarkan proses-proses yang akan dikerjakan dalam perancangan alat. Berikut ini perancangan alat pendeteksi gas CO menggunakan mikrokontroller ATMega 32, Berikut diagram bloknya seperti ditunjukkan pada gambar 1.berikut: 


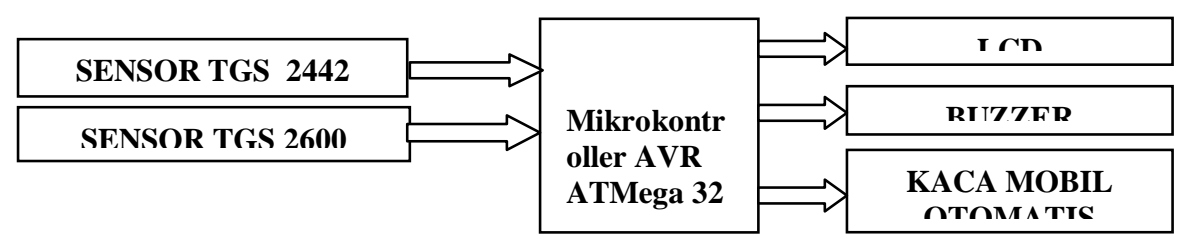

\section{Gambar 1. Blok Diagram Alat Pendeteksi Gas CO menggunakan Array sensor pada mobil}

Alat pendeteksi kebocoran gas CO ini akan bekerja yaitu Sensor TGS adalah sensor gas yang mendeteksi gas buang pada udara yang berupa gas CO. Jika gas CO tersebut telah terdeteksi maka sensor TGS akan memberi input (masukkan) ke mikrokontroller, kemudian dari mikrokontroller tersebut memiliki tiga output yakni LCD, buzzer (alarm) dan motor DC untuk mengerakkan kaca mobil secara otomatis. Dengan menggunakan dua sensor yaitu TGS 2442 dan TGS 2600. Kedua sensor tersebut memiliki sensitivitas yang berbeda. Sensor TGS 2442 berfungsi untuk mendeteksi polusi udara yang berasal dari gas buang kendaraan, seperti asap knalpot mobil atau motor. Sedangkan sensor TGS 2600 berfungsi untuk mendeteksi tingkat pencemaran udara oleh gas CO (karbonmonoksida). Apabila udara disekitar sensor tercemar maka kedua sensor ini akan segera bereaksi untuk mendeteksi udara disekitanya. Dalam menentukan kondisi udara maka digunakan lah fuzzy controller sebagai pengontrol dari kedua kondisi udara. Apabila LCD menampilkan tulisan "Status Aman", itu berarti kandungan gas CO didalam mobil tersebut dalam kondisi aman. Namun, apabila LCD menampilkan tulisan "Status bahaya" maka udara didalam mobil tersebut telah mengandung gas $\mathrm{CO}$ yang sangat berbahaya karena telah melebihi ambang batas maksimal udara yang telah ditetapkan. Kemudian buzzer akan berbunyi yang menandakan kebocoran gas $\mathrm{CO}$ yang berbahaya diikuti dengan kaca mobil yang akan terbuka secara otomatis. Apabila udara didalam mobil tersebut secara perlahan mulai menetral, maka secara otomatis pula buzzer akan mati, lalu output lainnya akan menyesuaikan, seperti tampilan pada LCD yang akan berubah menjadi "Status Aman". Driver motor berfungsi sebagai penghubung atau perangkat tambahan untuk menghubungkan antara mikrokontroler dengan motor DC yang merupakan penggerak kaca mobil otomatis terbuka.

Driver berfungsi sebagai penghubung tambahan untuk menghubungkan antara mikrokontroler dengan buzzer dan kipas. Penjelasan mengenai diagram alir alat pendeteksi gas CO pada menggunakan fuzzy controller dan array sensor dalam bentuk Gambar 2. berikut ini : 


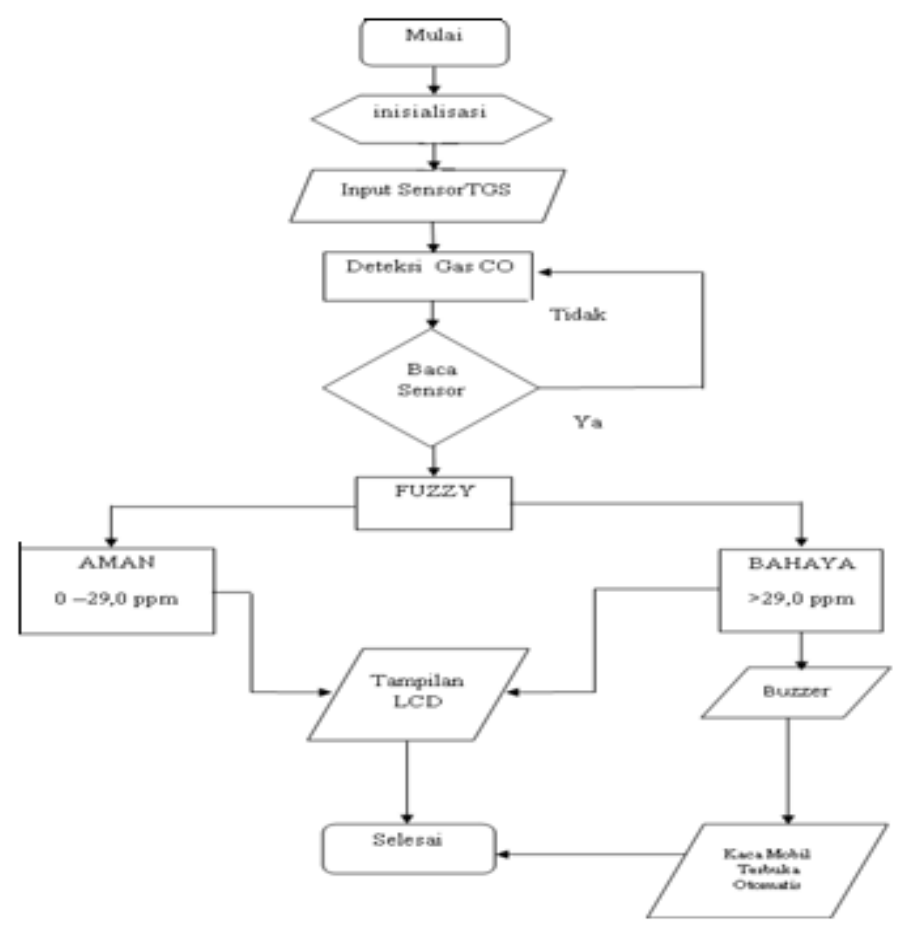

Gambar 2. Flowchart Sistem Alat Pendeteksi Gas CO

Adapun alur dan cara kerja pada diagram alur yaitu pertama melakukan inisialisasi serial lalu terlihat lah input dari gas CO, yang akan tampil dalam kadar gas. Kemudian fuzzy akan berkerja memfuzzykan gas 1 dan gas 2 . Apabila gas CO $0-29,0$ ppm maka LCD akan menampilkan 'Status aman", buzzer tidak aktif, dan kaca mobil tidak terbuka otomatis. Jika gas CO lebih besar dari >29,0 ppm maka LCD menampilkan "Status bahaya", buzzer aktif, diikuti dengan aktifnya motor DC yang membuka kaca mobil secara otomatis. Setelah hal ini dilakukan maka flowchart kerja dari sistem mikrokontroler kembali mengulang kembali dari awal program.

Untuk mendeteksi gas $\mathrm{CO}$ sensor terhubung ke ADC mikrokontroler di port $\mathrm{D}$ dengan tegangan 5 volt DC dengan range ADC 0 - 1023 untuk nilai ADCnya. Untuk pendeteksian gas $\mathrm{CO}$ ditetapkan bahwa nilai maksimal sensor untuk mendeteksi gas $\mathrm{CO}$ adalah sebesar $30 \mathrm{ppm}$. Dari ketetapan tersebut didapatkan fungsi keanggotaan gas CO untuk nilai fungsi keanggotaannya dengan range $0-30 \mathrm{ppm}$. Maka agar skala fungsi keanggotaannya sesuai yaitu 30 ppm maka nilai ADC harus dibagi dengan 34 yang dapat dicari dengan persamaan berikut :

Nilai pembagi $\mathrm{ADC}=\underline{\text { Nilai } A D C}$

$$
\mathrm{CO}(\mathrm{ppm})
$$

Keterangan :

$\mathrm{CO}(\mathrm{ppm}) \quad=$ Kadar gas $\mathrm{CO}$ maksimal yang diinginkan

Nilai ADC $=1023$

Maka, dapat kita masukkan nilainya

Nilai pembagi $\mathrm{ADC}=\frac{1023}{30 \mathrm{ppm}}$

Nilai pembagi $\mathrm{ADC}=34$

fungsi keanggotaannya untuk input sensor gas $\mathrm{CO}$ memainkan peranan yang sangat penting untuk merepresentasikan masalah dan menghasilkan keputusan yang akurat. Fungsi keanggotaan adalah suatu kurva yang menunjukan pemetaan titik-titik 
input data kedalam nilai keanggotaannya (derajat keanggotaan) yang memiliki interval antara 0 (nol) sampai 1 (satu). Secara matematis fungsi keanggotaan dari ke dua sensor ini dapat dituliskan sebagai Gambar 3. Input Sen 1 (TGS 2442) dan Gambar 4. Input Sen 2 (TGS 2600) berikut :

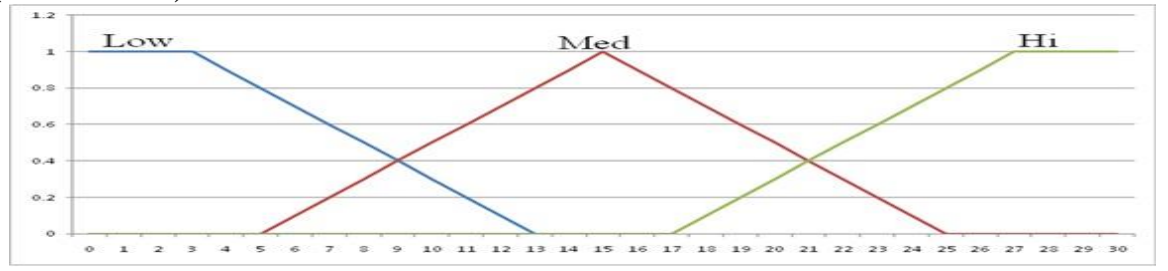

Gambar 3. MBF untuk Sen1 (TGS 2442)

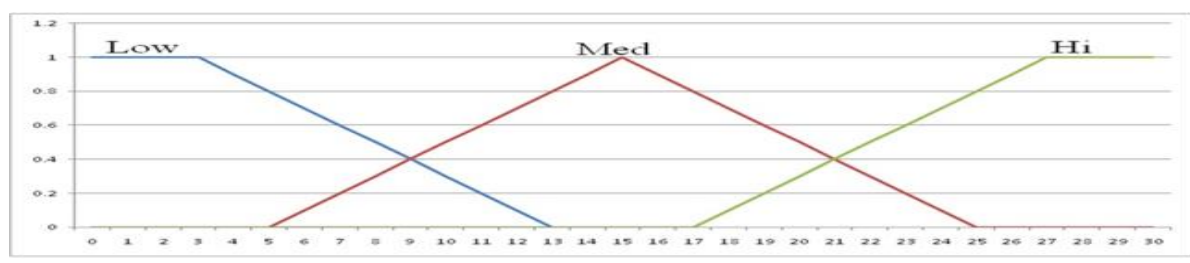

Gambar 4. MBF untuk Sen1 (TGS 2600)

Input dari proses defuzzyfication adalah suatu himpunan fuzzy yang diperoleh dari komposisi aturan-aturan fuzzy, sedangkan output yang dihasilkan merupakan suatu bilangan pada domain himpunan fuzzy tersebut, sehingga jika diberikan suatu himpunan fuzzy dalam range tertentu, maka harus dapat diambil suatu nilai crisp tertentu sebagai keluarannya.

Tabel 1. Pengujian dan pengukuran Sensor Gas CO

\begin{tabular}{|c|c|c|c|c|c|c|}
\hline & $\begin{array}{c}\text { Pengujian } \\
\text { Ke }\end{array}$ & $\begin{array}{c}\text { TGS 2442 } \\
\text { Gas1(ppm) }\end{array}$ & $\begin{array}{c}\text { TGS 2600 } \\
\text { Gas1 }(\mathbf{p p m})\end{array}$ & $\begin{array}{c}\text { Vout } \\
\text { Gas1 }\end{array}$ & $\begin{array}{c}\text { Vout } \\
\text { Gas2 }\end{array}$ & $\begin{array}{c}\text { Output } \\
\text { gas1/gas2 }\end{array}$ \\
\hline \multirow{3}{*}{ Aman } & $\mathbf{1}$ & $5 \mathrm{ppm}$ & $11 \mathrm{ppm}$ & $0.82 \mathrm{v}$ & $1.82 \mathrm{v}$ & $8.2 \mathrm{ppm}$ \\
\cline { 2 - 7 } & $\mathbf{2}$ & $8 \mathrm{ppm}$ & $16 \mathrm{ppm}$ & $1.33 \mathrm{v}$ & $2.65 \mathrm{v}$ & $12.1 \mathrm{ppm}$ \\
\cline { 2 - 7 } & $\mathbf{3}$ & $7 \mathrm{ppm}$ & $14 \mathrm{ppm}$ & $1.14 \mathrm{v}$ & $2.31 \mathrm{v}$ & $10.7 \mathrm{ppm}$ \\
\cline { 2 - 7 } & $\mathbf{4}$ & $12 \mathrm{ppm}$ & $18 \mathrm{ppm}$ & $1.98 \mathrm{v}$ & $2.97 \mathrm{v}$ & $15.3 \mathrm{ppm}$ \\
\cline { 2 - 7 } & $\mathbf{5}$ & $16 \mathrm{ppm}$ & $21 \mathrm{ppm}$ & $2.63 \mathrm{v}$ & $3.47 \mathrm{v}$ & $18.9 \mathrm{ppm}$ \\
\cline { 2 - 7 } & Rata-rata & $\mathbf{9 . 6} \mathbf{~ p p m}$ & $\mathbf{1 6} \mathbf{~ p p m}$ & $\mathbf{1 . 5 8} \mathbf{v}$ & $\mathbf{2 . 6 4} \mathbf{v}$ & $\mathbf{1 3 . 0 4} \mathbf{~ p p m}$ \\
\hline Bahaya & $\mathbf{1}$ & $22 \mathrm{ppm}$ & $30 \mathrm{ppm}$ & $3.64 \mathrm{v}$ & $4.96 \mathrm{v}$ & $29.1 \mathrm{ppm}$ \\
\cline { 2 - 7 } & $\mathbf{2}$ & $21 \mathrm{ppm}$ & $30 \mathrm{ppm}$ & $3.48 \mathrm{v}$ & $4.98 \mathrm{v}$ & $29.1 \mathrm{ppm}$ \\
\cline { 2 - 7 } & $\mathbf{3}$ & $21 \mathrm{ppm}$ & $30 \mathrm{ppm}$ & $3.47 \mathrm{v}$ & $4.97 \mathrm{v}$ & $29.1 \mathrm{ppm}$ \\
\cline { 2 - 7 } & $\mathbf{4}$ & $23 \mathrm{ppm}$ & $30 \mathrm{ppm}$ & $3.82 \mathrm{v}$ & $4.98 \mathrm{v}$ & $29.3 \mathrm{ppm}$ \\
\cline { 2 - 7 } & $\mathbf{5}$ & $22 \mathrm{ppm}$ & $30 \mathrm{ppm}$ & $3.64 \mathrm{v}$ & $4.98 \mathrm{v}$ & $29.2 \mathrm{ppm}$ \\
\cline { 2 - 7 } & Rata-rata & $\mathbf{2 1 . 8} \mathbf{~ p p m}$ & $\mathbf{3 0} \mathbf{p p m}$ & $\mathbf{3 . 6 1} \mathbf{v}$ & $\mathbf{4 . 9 7} \mathbf{v}$ & $\mathbf{2 9 . 1 6} \mathbf{~ p p m}$ \\
\hline
\end{tabular}

Dalam pengukuran nilai sensor dapat dilihat bahwa berdasarkan ketentuan yang telah dibuat dalam system fuzzy guna mengontrol kadar gas $\mathrm{CO}$ didalam mobil yang tertutup terlihat bahwa semakin besar kadar gas yang dapat dideteksi oleh sensor maka akan semakin besar nilai tegangan yang dihasilkan oleh masing-masing sensor.

Berdasarkan hasil pengujian dengan melakukan 5 kali uji coba maka didapat nilai pengukuran rata-rata gas yang terdeteksi aman adalah gas 1 bernilai $9.6 \mathrm{ppm}$ dan gas 2 bernilai $16 \mathrm{ppm}$, sedangkan untuk tegangan keluaran masing-masing gas adalah gas 1 bernilai $1.58 \mathrm{~V}$, Volt gas 2 bernilai $2.64 \mathrm{~V}$ sementara rata-rata Output nya bernilai $13.04 \mathrm{ppm}$. Sedangkan gas yang terdeteksi bahaya didapatkan rata-rata gas 1 bernilai 
$21.8 \mathrm{ppm}$, gas 2 bernilai $30 \mathrm{ppm}$, untuk tegangan keluran Volt gas 1 adalah $3.61 \mathrm{~V}$, Volt gas 2 adalah $4.97 \mathrm{~V}$, dan untuk rata-rata Output nya bernilai 29.16 ppm.

\section{Kesimpulan dan Saran}

Berdasarkan rumusan masalah, hasil penelitian, dan pembahasan yang disajikan sebelumnya dapat ditarik kesimpulan sebagai berikut:(1) Hasil penelitian Berdasarkan pengujian yang telah dilakukan pada alat pendeteksi kebocoran gas beracun CO pada mobil menggunakan array sensor dengan fuzzy controller maka penulis menyimpulkan dengan sistem logika fuzzy dengan menggunakan metode defuzzifikasi metode COA (centre of area) didapatkan kondisi ketika sensor aktif kadar gas $\mathrm{CO}$ yang terdeteksi menunjukkan keluaran $<29.0$ ppm maka LCD akan menampilkan "status aman" dan apabila kadar gas CO yang terdeteksi mencapai >29.0 ppm maka LCD menampilkan "status bahaya" dan buzzer menyala diikuti oleh motor DC yang menggerakkan turun kaca mobil secara otomatis. (2) Untuk rata-rata selisih error output gas didapatkan nilai sebesar 0.29 ppm disaat kondisi aman dan 3.87 ppm disaat kondisi bahaya.

\section{Daftar Pustaka}

Bejo, Agus.2008. C dan AVR Rahasia Kemudahan Bahasa C dalam Mikrokontroler ATMega8535. Yogyakarta:Graha Ilmu.

Chandra, Franky \& Deni Arifianto.2010.Jago Elektronika.Jakarta: Kawan Pustaka.

Hartono, Jogiyanto.2006.Konsep Dasar Pemrograman Bahasa C EDISI IV.Yogyakarta:ANDI.

Kusumadewi, Sri \& Hari Purnomo.2010.APLIKASI LOGIKA FUZZY untuk Pendukung Keputusan.Yogyakarta:Graha Ilmu.

Kusumadewi, Sri \& Sri Hartati.2010.NEURO-FUZZY Integrasi Sistem Fuzzy \& Jaringan Syaraf.Yogyakarta:Graha Ilmu.

Prihono.2009.Jago Elektronika Secara Otodidak.Jakarta: Kawan Pustaka.

Winoto, Ardi.2010.Mikrokontroler AVR ATMega8/16/32/8535 dan Pemrogramanya dengan Bahasa C pada WinAVR.Bandung:Informatika.

Dikman, Slachsa. Prototype Pembersih dan Monitoring Asap Rokok Pada Ruang Tertutup Menggunakan Fuzzy Logic Controller.Politeknik Teknik Elektro, Surabaya. Diakses Tanggal 28 juni 2012

Wahyudi, Implementasi Fuzzy Logic Controller pada Sistem Pengereman Kereta Api. Teknik Elektro. Universitas Diponegoro, Semarang. Diakses Tanggal 28 juni 2012

P Bagus, Romidian \& dkk. Pemodelan dan Pengujian Sensor TGS2600 untuk Aplikasi Sistem Monitoring Kandungan Gas Karbon Monoksida (CO) di Udara. Teknik Elektro. Universitas Diponegoro, Semarang. Diakses Tanggal 28 juni 2012

Atmel.ATmega32 Datasheet.

(www.atmel.com) Diakses tanggal 30 Juni 2012

Figaro USA Inc.2007.TGS 2442-for the detection of Carbon Monoxide. (www.figarosensor.com) Diakses tanggal 03 Februari 2012

Figaro USA Inc.2007.TGS 2600-for the detection of Air Contaminants. (www.figarosensor.com) Diakses tanggal 03 Februari 2012

POM Indonesia.2005. Keracunan yang Disebabkan Gas Karbon Monoksida. (www.pom.go.id) Diakses tanggal 17 Januari 2012

Keputusan Kepala Bapedal No.107 Tahun 1997.

(http://www.menkokesra.go.id) Diakses tanggal 17 Januari 2012 
220 Slamet Widodo, et al.

Peraturan Pemerintah Republik Indonesia Nomor 41 Tahun 1999.

(www.proxsis.com) Diakses tanggal 17 Januari 2012

www.delta-electronik.com/sensorgasfigaroTGS2600, Diakses 17 Mei 2013 